\title{
Pelatihan Terapi Relaksasi Hypnobirthing Untuk Tenaga Kesehatan Dalam Rangka Meningkatkan Pelayanan Kesehatan Ibu Dan Anak
}

\author{
Lutfiana Puspita Sari $^{1^{*}}$, Triwik Sri Mulati ${ }^{2}$ \\ ${ }^{1,2}$ Jurusan Kebidanan, Poltekkes Kemenkes Surakarta \\ *Email: lutfiana@poltekkes-solo.ac.id
}

\begin{abstract}
Background: labor pain is a real problem for maternity mothers, as many as $90 \%$ of women experience pain during childbirth. Mothers who are about to give birth expect to be able to give birth with a sense of comfort, but in reality many health workers, especially midwives, do not understand how to accompany mothers in labor and teach the correct relaxation techniques to reduce labor pain. The hypnobirthing relaxation technique is a natural pain reduction program by utilizing the subconscious mind to believe that childbirth is a natural, comfortable, and normal process that pregnant women can learn during their pregnancy. Methods: Method this study is used relaxation hypnobirthing intervention. The sample of this study were all midwives in the South Klaten Public Health Center area. The researcher demonstrated hypnobirthing relaxation and then the respondents practiced it in pairs. Results: the average value of the knowledge of the midwives before the training on hypnobirthing relaxation was only 50, after the training the knowledge increased by 90. Hypnobirthing relaxation training can increase knowledge and skills of midwives to in assisting pregnant women during their pregnancy and lead pregnant women to a comfortable, smooth, natural, and normal labor.

Conclusion: Hypnobirthing relaxation training for midwives can increase their knowledge in assisting mothers in childbirth so that they can relax in the face of childbirth.
\end{abstract}

Keywords: hypnobirthing, labor, midwives;

\section{PENDAHULUAN}

Kehamilan dan persalinan merupakan sebuah peristiwa yang alami dan fisiologis. Namun terkadang tidak sedikit juga wanita mengalami berbagai komplikasi pada saat kehamilan maupun persalinannya yang dipengaruhi oleh beberapa faktor. Sebuah proses persalinan dibutuhkan adanya kontraksi rahim untuk mendukung proses pembukaan serviks. Namun tidak semua wanita yang menjalani proses persalinan menyadari akan hal ini dan menganggap nyeri persalinan sebagai suatu hal yang menakutkan.

Nyeri persalinan yang dialami oleh setiap wanita yang akan bersalin adalah suatu proses yang fisiologis. Tercatat sebanyak $90 \%$ wanita mengalami nyeri saat bersalin. Ibu bersalin mengharapkan sebuah proses persalinan dengan minimalis rasa nyeri. Sehingga tidak sedikit wanita yang memutuskan untuk bersalin secara seksio sesarea. Tingginya angka kejadian seksio sesarea salah satu penyebabnya karena para ibu bersalin lebih memilih persalinan yang relatif tidak nyeri (Cunningham, Mac Donald, 2005).

Berdasarkan hasil penelitian menyatakan bahwa $96.5 \%$ determinan nonmedis ibu bersalin memutuskan persalinan secara seksio sesarea disebabkan oleh rasa sakit pada persalinan (Potter, 2006). Ketidaktahuan ibu hamil dalam memutuskan pilihan yang tepat untuk proses persalinannya terkadang hanya dikarenakan sugesti negative yang sudah tertanam dalam pikiran bawah sadarnya bahwa persalinan itu nyeri dan sakit.

Persalinan sering kali digambarkan sebagai salah satu penyebab rasa nyeri yang paling kuat yang pernah dialami. Kuatnya ketakutan dan kecemasan yang dialami ibu berkaitan dengan semakin besarnya rasa sakit yang dialami (WHO, 2015). Rasa takut menyebabkan ketegangan pada tubuh terutama pada rahim. Kondisi ini dapat 
menghambat proses persalinan alami, memperlama persalinan, dan menimbulkan nyeri yang hebat.

Nyeri persalinan memiliki sifat yang unik, mencerminkan kondisi yang normal, dan bukan merupakan respons dari suatu keadaan patologis. Nyeri yang timbul sebenarnya merupakan sebuah sinyal yang menandakan bahwa proses persalinan telah dimulai yang ditandai dengan rahim mulai berkontraksi secara intens dengan frekuensi semakin sering, durasi semakin lama.

Saat ini banyak ibu hamil menaruh perhatian lebih akan rasa nyeri yang mungkin dihadapi saat persalinan dan juga metode penghilang rasa sakit saat persalinan yang tersedia. Namun, masih sangat sedikit ibu bersalin yang menerapkan teknik pengurangan rasa nyeri persalinan dengan hypnotheraphy. Ada dua metode yang dapat meringankan rasa nyeri yaitu metode farmakologi (pemberian obat-obatan analgesik, opiat) dan metode nonfarmakologi/alamiah (pijatan, akupuntur, relaksasi, hidroterapi, hipnosis, music).

Metode alamiah ini dapat membantu ibu untuk tetap rileks, tenang dan terkendali dalam menghadapi nyeri (Christian, 2012). Saat ini perkembangan ilmu kesehatan menekankan pendekatan holistik dengan memperhatikan aspek psycho-neuroendocrino-immune (PNEI), yang menjelaskan bahwa ketidakselarasan jiwa dan pikiran akan mengakibatkan gangguan keseimbangan saraf, hormon, dan akhirnya daya tahan tubuh. Sama halnya dengan perkembangan dalam asuhan persalinan, asuhan yang kini diberikan bertujuan memberi rasa nyaman, aman dan menyenangkan, serta mengurangi rasa cemas yang menegangkan.

Salah satu metode nonfarmakologis mind-body intervention yang dapat diterapkan dalam mencegah atau mengurangi kecemasan ibu hamil, yaitu hypnoterapi. Hypnobirthing merupakan praktik hypnosis terhadap diri sendiri/ self hypnosis yang digunakan dalam menghadapi dan menjalani kehamilan serta persiapan melahirkan dengan cara alami, tenang dan nyaman serta menyiapkan kesehatan jiwa dari janin. Teknik ini melibatkan relaksasi mendalam, pola pernapasan lambat dan petunjuk cara melepaskan endorfin dari dalam tubuh yang memungkinkan calon ibu menikmati proses kelahiran dengan nyaman.

Beberapa penelitian sebelumnya membuktikan bahwa hypnobirthing secara bermakna memperpendek kala I dan II, mengurangi kecemasan saat menjalani proses persalinan, mengurangi penggunaan analgetik, mengurangi nyeri saat persalinan, mengurangi risiko terjadinya operasi sesar, serta mengurangi distres saat persalinan. Penelitian di Indonesia pernah dilakukan oleh (Andriyani, 2014) terbukti bahwa metode hypnobirthing secara signifikan dapat mengurangi kecemasan menghadapi persalinan.

Bidan merupakan orang yang paling dekat dengan ibu hamil dan dijadikan sebagai sarana untuk sharing beberapa keluhan yang dialami oleh ibu hamil termasuk dalam emmpersiapkan proses persalinan. Banyaknya bidan belum menjamin seorang ibu bersalin dapat menjalani proses persalinanya dengan minim rasa nyeri. Permasalahan yang ada belum banyak bidan yang mengetahui dan mempraktekkan pengurangan rasa nyeri persalinan dengan teknik hypnobirthing. Karena dibutuhkan biaya yang tidak cukup murah untuk mengikuti pelatihan relaksasi hypnobirthing yang berkualitas. Sehingga kurang maksimal dalam melakukan pendampingan kepada ibu bersalin.

Ibu bersalin pun semakin cemas dan tegang karena merasakan nyeri persalinan. Pada saat pertemuan rutin IBI dilakukan wawancara dengan 10 bidan desa wilayah puskesmas klaten selatan bahwa para bidan belum pernah mengikuti pelatihan tentang hypnobirthing. Dengan permasalahan ini maka perlu dilakukan pelatihan bagi para 
bidan tentang teknik hypnobirthing agar dapat mendampingi ibu bersalin untuk meminimkan rasa nyeri persalinan. Berdasarkan fenomena tersebut maka perlu dilakukan pengabdian masyarakat dengan tema 'Pelatihan Terapi Relaksasi Hypnobirthing Untuk Tenaga Kesehatan Dalam Rangka Meningkatkan Pelayanan Kesehatan Ibu dan Anak di Wilayah Puskesmas Klaten Selatan '.

\section{TINJAUAN PUSTAKA}

Association for Prenatal and Perinatal Psychology and Health (APPPAH) tahun 2012 dalam penelitian outcame hypnobirthing merekomendasikan hypnobirthing sebagai terapi komplementer pelayanan konvensional asuhan prenatal dan persalinan. Dalam penelitian tersebut melaporkan bahwa hypnobirthing secara bermakna mengurangi: induksi, penggunaan cairan intravena, penggunaan pitocin, penggunaan anastesi intravena maupun epidural, oprasi cesar, persalinan di Rumah Sakit (meningkatkan kemungkinan lahir di home birth center oleh Bidan) (Phillips-Moore, 2012).

Hypnobirthing merupakan kombinasi praktik hipnosis terhadap diri sendiri/autohypnosis (self-hypnosis) dengan panduan dari hipnoterapis untuk mencapai relaksasi mendalam. Hypnobirthing dapat digunakan untuk menghadapi dan menjalani kehamilan serta persiapan melahirkan dengan cara alami, tenang dan nyaman, serta kesehatan jiwa janin. Hypnobirthing memiliki beberapa manfaat di antaranya mengurangi kebutuhan obat-obatan pereda nyeri, meningkatkan kejadian persalinan spontan, mengurangi risiko operasi, mempercepat pemulihan ibu postpartum, membantu menjaga suplai oksigen kepada bayi selama proses persalinan sehingga bayi yang lahir memiliki nilai APGAR yang lebih baik, serta mempercepat durasi persalinan (Kuswandi, 2011).

Sebuah penelitian menunjukkan penggunaan hipnosis dapat menurunkan persepsi terhadap nyeri secara signifikan. Hipnosis membantu ibu untuk dapat rileks. Pada saat ibu dalam keadaan rileks, maka sekresi kotekolamin menurun, sedangkan sekresi endorfin sebagai opiat alami tubuh meningkat sehingga memberikan efek pereda nyeri. Namun tidak semua tenaga kesehatan dapat memberikan serta mengajarkan teknik relaksasi hypnobirthing kepada ibu hamil. Diperlukan sebuah pelatihan khusus untuk dapat memberikan serta mendampingi ibu hamil melakukan relaksasi hypnobirthing sehingga apa yang diajarkan tepat dan sesuai dengan ilmu hypnobirthing.

Tenaga kesehatan yang menguasai teknik hypnobirthing hal ini merupakan salah satu bentuk support atau dukungan emosional kepada ibu bersalin, sehingga mereka mampu mengatasi ketakutan, kekhawatiran, dan kecemasan dalam menghadapi persalinan. Ibu bersalin yang mengalami ketakutan terhadap proses persalinan akan memberikan dampak negatif dan juga memberikan trauma tersendiri terhadap proses persalinan (Isbir, 2017).

Memberikan informasi atau edukasi kepada wanita selama persalinan akan memberikan kenyamanan fisik dan emosional tersendiri bagi wanita tersebut. Sehingga Teknik hypnobirthing perlu diajarkan kepada ibu hamil pada saat kehamilan sehingga pada saat persalinan sugesti dan afirmasi yang ditanamkan sejak kehamilan benar-benar terjadi dan menjadi sebuah kenyataan. Hal ini merupakan salah satu strategi koping untuk mempersiapkan persalinan dengan cara meningkatkan efikasi diri, mengurangi rasa sakit serta kecemasan. Pemberdayaan diri yang dilakukan selama kehamilan mampu meningkatkan kepercayaan diri bagi wanita untuk bisa mengelola persalinannya kelak dan mengurangi trauma terhadap proses persalinan (Ferguson, 2013). 


\section{DESAIN PENELITIAN}

Kegiatan pengabdian masyarakat ini, Sasarannya adalah seluruh tenaga Kesehatan baik dokter maupun bidan yang berada di wilayah kerja puskesmas klaten selatan sejumlah 20 tenaga kesehatan yang bersedia untuk mengikuti pelatihan relaksasi hypnobirthing yang dibuktikan dengan mengisi lembar informed consent sebelumnya. Kegiatan Pengabmas ini dilaksanakan pada tanggal 11 April 6 Mei 2020 pukul 08.0014.00 WIB. Pelaksanaan program kegiatan Pengabmas terdiri dari beberapa tahapan, antara lain pemberian materi tentang Teknik hypnobirthing dasar.

Sebelum menyampaikan materi, tim melakukan pre-test terkait relaksasi hypnobirthing. Instrumen yang digunakan untuk mengukur pengetahuan para bidan dan dokter berupa item pernyataan Langkah-langkah dalam melakukan Teknik hypnosis dasar yang sering disebut dengan 'PRITKIT (Preparation, Relaksasi, Induksi, Test, Konsolidasi, Implantasi, Test"'. Instrument ini sudah baku berupa tahapan Langkahlangkah unutk melakukan hypnosis dasar sehingga tidak dierlukan uji validitas dan reliabilitas.

Instrumen ini adalah untuk mengetahui seberapa jauh pengetahuan peserta tentang hypnobirthing. Setelah pre-test selesai, tim menyampaikan secara singkat terlebih dahulu tentang teori dan tahapan relaksasi hypnobirthing. Pemberian materi ini bertujuan untuk meningkatkan pengetahuan para tenaga Kesehatan tentang teknik hypnobirthing. Peserta juga diberikan booklet yang berisi tentang tahapan relaksasi dasar untuk hypnobirthing. Booklet tersebut dapat dijadikan pegangan serta panduan dalam mengaplikasikan teknik hypnobirthing baik untuk relaksasi pribadi maupun kepada ibu hamil.

Dengan Booklet ini juga dapat lebih meningkatkan kemampuan para tenaga Kesehatan dalam mempraktekkan hypnosis dasar baik untuk dipergunakan bagi dirinya sendiri maupun kepada pasien serta dapat meningkatkan dan mendukung program pemerintah menurunkan angka kematian ibu dengan memberdayakan serta mencerdaskan ibu hamil sejak masa kehamilan sehingga siap dalam menghadapi persalinan dan menurunkan risiko komplikasi yang terjadi pada saat persalinan.

Pelatihan Teknik Hypnobirthing; Tim pengabmas melakukan demonstrasi dengan cara mempraktikkan secara langsung tahapan relaksasi dasar dimulai dari awal preparation sampai dengan mengakhiri proses relaksasi tersebut. Setelah itu tim, meminta peserta untuk mengikuti apa yang dipraktekan sebelum peserta praktik dengan pasangan masing-masing/sesama peserta. Semua peserta wajib praktek secara bergantian dengan rekannya dengan didampingi oleh tim.

Teknik hypnobirthing ini dilakukan langkah demi langkah sesuai dengan yang tertulis di booklet dan yang sudah dipraktekkan oleh tim pengabmas. Teknik hypnobirthing ini efektif untuk dilakukan saat kehamilan Trimester I sampai dengan menjalani proses persalinan. Sebagai bentuk evaluasi, peserta wajib melakukan redemonstrasi Teknik Hypnobirthing antar teman. Redemonstrasi dilakukan secara bergantian dengan menerapkan semua langkah-langkah tahapan hypnosis dasar.

Keberhasilan dari teknik hypnobirthing ini adalah ketika perserta mampu melakukan self hypnosis untuk kehidupan sehari-hari dan mengajarkan kepada ibu hamil.

\section{HASIL PENELITIAN}

Kegiatan pengabdian masyarakat yang dilakukan di wilayah kerja Puskesmas Klaten Selatan memberikan hasil tim pengabmas melakukan evaluasi tentang 
pengetahuan dan keterampilan peserta dengan cara melakukan pengukuran pre dan post tentang relaksasi hypnobirthing melalui questioner dan standar operating prosedur (SOP) teknik relaksasi hypnobirthing. Tim mempersiapkan questioner yang berisi pertanyaan secara terstruktur. Pre-Test didapatkan hasil rata-rata responden dapat menjawab $40 \%$ dari pertanyaan yang diberikan dengan nilai rata-rata 40 .

Langkah selanjutnya adalah pemberian materi beserta demonstrasi teknik relaksasi hypnobirthing. Responden yang hadir sangat bersemangat dan aktif bertanya tentang materi yang disampaikan serta antusias dalam mendemonstrasikan teknik relaksasi hypnobirthing antar teman. Evaluasi pelatihan yang dilakukan dengan cara mengerjakan post test dan mempraktekkan teknik relaksasi hypnobirthing antar teman.

Hasil evaluasi terjadi peningkatan, dengan rata-rata peningkatan nilai sebesar 50 poin sehingga nilai pengetahuan tenaga kesehatan meningkat menjadi rata-rata 90 bahkan tidak sedikit peserta yang mendapat nilai 100. Mayoritas responden sebesar $90 \%$ dapat menjawab pertanyaan dengan tepat, dapat menjelaskan kembali serta mempraktekkan tentang penatalaksanaan relaksasi hypnobirthing untuk mengurangi kecemasan selama kehamilan serta mengurangi nyeri persalinan. Evaluasi tentang teknik relaksasi hypnobirthing dapat dilihat pada table berikut;

Tabel 1. Evaluasi tentang relaksasi hypnobirthing

\begin{tabular}{lcc}
\hline Nama & $\begin{array}{c}\text { Pengetahuan relaksasi } \\
\text { hypnobirthing (Pre) }\end{array}$ & $\begin{array}{c}\text { Pengetahuan relaksasi } \\
\text { hypnobirthing (Post) }\end{array}$ \\
\hline Bd.Tr & 50 & 100 \\
Bd.Si & 40 & 100 \\
Bd.Sy & 40 & 90 \\
Bd.Mr & 30 & 90 \\
Bd.Ts & 50 & 90 \\
dr Ms & 40 & 100 \\
dr Tw & 60 & 90 \\
Bd Hr & 40 & 90 \\
Bd.Mw & 40 & 90 \\
Bd. Rs & 50 & 90 \\
Bd.Na & 60 & 100 \\
Bd.ys & 40 & 90 \\
Bd.Dw & 50 & 90 \\
Bd.Mr & 50 & 90 \\
Bd.Cl & 20 & 90 \\
Bd.Fd & 30 & 90 \\
Bd.Nt & 40 & 90 \\
Bd.Mr & 40 & 90 \\
Bd.Kl & 50 & 100 \\
Bd.Mrm & 60 & 100 \\
\hline
\end{tabular}

Berdasarkan table diatas terlihat jelas setelah diberikan materi dan praktik tentang hypnobirthing nampak terjadi peningkatan pengetahuan yang signifikan tentang relaksasi hypnobirthing. Relaksasi hypnobirthing ini dapat dipraktekkan dirumah minimal dilakukan $2 \mathrm{x}$ dalam sehari dengan waktu sesuai dengan kondisi masingmasing. Dilakukan secara konsisten, Hal ini pun nanti yang akan dilatihkan oleh pasien masing-masing, karena keberhasilan dari hypnobirthing tersebut adalah Ketika pasien 
mampu melakukan self hypnosis tanpa didampingi oleh terapist

\section{PEMBAHASAN}

Berdasarkan hasil evaluasi menunjukkan bahwa ada perbedaan yang signifikan pengetahuan dan keterampilan tenaga kesehatan antara sebelum dan sesudah dijelaskan serta didemonstrasikan tentang relaksasi hypnobirthing. Banyak faktor yang mempengaruhi peningkatan pengetahuan seseorang salah satunya adalah melalui edukasi dari tenaga yang memiliki kualifikasi di bidangnya agar ilmu dan materi yang disampaikan benar-benar dikuasai dan dapat disampaikan dengan baik kepada peserta.

Dokter dan bidan adalah orang yang sangat dekat dengan klien terutama saat persalinan. Meskipun dokter dan bidan bukan keluarga dari ibu hamil tersebut, namun peran tenaga kesehatan disni sangatlah penting. Dokter dan bidan dapat memberikan support kepada ibu bersalin dengan melakukan terapi non farmakologi untuk mengurangi kecemasan, ketakutan, ketidaknyamanan saat merasakan gelombang rahim datang serta kelelahan akibat ketidaknyamanan yang terjadi selama proses persalinan. Bentuk dukungan yang dapat diberikan oleh dokter dan bidan saat menjelang proses pessalinan lainnya adalah dengan memberikan dukungan dan kenyamanan fisik melalui sentuhan yang lembut sebagai wujud emphaty kepada ibu bersalin, dukungan emosional, dukungan informasional dan dukungan advokasi (Isbir, 2017).

Salah satu bentuk dukungan emosional yang bisa dilakukan oleh dokter dan bidan sejak kehamilan adalah mencerdaskan serta memberdayakan ibu hamil sejak awal kehamilan dengan melatih beberapa exercise dan teknik relaksasi untuk menghadapi persalinan. Teknik relaksasi yang dapat dilakukan adalah dengan relaksasi hypnobirthing. Wanita yang sudah terbiasa menerapkan relaksasi hypnobirthing selama kehamilannya akan merasakan kenyamanan dan bisa mengendalikan emosinya dengan baik pada saat persalinan (Uludağ, 2021).

Teknik relaksasi Hypnobirthing adalah program untuk menanamkan sugesti kea lam bawah sadar, menerima kehamilan dengan baik, mereprogramming sugesti negative bahwa 'melahirkan itu sakit' dengan sebuah afirmasi dan sugesti positif tentang sebuah persalinan yang indah, nyaman, lancer dan alami. Menyadari kekuatan terbesar pada tubuh serta menyerahkan semuanya tentang proses persalinan kepada tubuh dan bayi sehingga harapannya tubuh, bayi dan ibu dapat bekerjasama dengan baik untuk menjalani sebuah persalinan yang aman dan nyaman serta bebas trauma (PhillipsMoore, 2012).

Ketakutan yang dimiliki oleh ibu bersalin akan meningkatkan hormon stress yaitu kortisol dan katekolamin. Pada saat hormon ini aktif maka akan mempengaruhi kontraksi uterus yang semakin hebat serta menutupnya serviks. Hal inilah yang terjadi ketika tubuh tegang, dan stress maka akan merasakan nyeri yang semakin hebat serta kegagalan dalam kemajuan pembukaan serviks yang akan berdampak terhadap persalinan lama. Wanita yang sudah terbiasa melakukan self hypnosis, tubuh akan mengeluarkan hormone endorphin dan relaksan sehingga ibu dapat dengan nyaman merasakan gelombang rahim datang serta serviks akan membuka dengan sangat lembut serta pembukaan serviks berlangsung dengan cepat (Swencionis, 2012).

Berbagai penelitian telah dilakukan untuk mengetahui efektivitas hypnobirthing terhadap proses persalinan. Seperti penelitian yang telah dilakukan oleh Sari dan Rosalinna (2019) bahwa relaksasi hypnobirthing dapat mengurangi kecemasan pada ibu bersalin dan nyeri persalinan saat kala I fase aktif serta mempercepat kala II (Puspita Sari, 2019). Penelitian yang lain juga telah dilakukan oleh (Muflihah, 2013) bahwa 
hypnobirthing berperan besar terhadap proses persalinan. Hypnobirthing membantu memberikan kesiapan mental dan keyakinan untuk melahirkan secara alami dengan rasa sakit yang minimal.

Hypnobirthing adalah sebuah paradigma baru untuk mengajarkan sebuah proses persalinan secara alami. Teknik ini melibatkan relaksasi yang mendalam, pola pernafasan lambat, dan bagaimana endorphin dilepaskan oleh tubuh sehingga ibu dapat menikmati proses persalinan yang lembut, aman, cepat dan alami. Dengan proses yang sangat nyaman sehingga harapannya ibu dapat berkonsentrasi mengejan untuk kelancaran proses persalinannya. Sehingga dapat disimpulkan bahwa hypnobirthing penting untuk diberikan kepada ibu hamil sejak awal kehamilannya demi kelancaran proses persalinan.

\section{KESIMPULAN DAN SARAN}

Kesimpulan dari hasil kegiatan pengabdian kepada masyarakat ini adalah pelatihan teknik relaksasi hypnobirthing sangat baik untuk dilatihkan kepada tenaga kesehatan agar dapat memberikan inovasi pada kegiatan kelas ibu hamil sehingga dapat mencerdaskan ibu hamil sejak kehamilannya sehingga dapat mempersiapkan proses persalinan dengan baik. Setelah dilakukan pelatihan, pengetahuan peserta rata-rata mengalami kenaikan dibandingkan sebelum diberikan pelatihan sebesar 90-100\%.

Agar teknik relaksasi hypnobirthing ini dapat diaplikasikan pada fasilitas pelayanan kesehatan dasar dan dijadikan inovasi program pada kelas ibu hamil demi kesehatan jiwa dan fisik ibu hamil sampai dengan proses persalinan. Dengan berlatih secara rutin harapannya afirmasi yang dimasukkan dalam pikiran bawah sadar benarbenar terekam dan menjadi sebuah kenyataan untuk sebuah proses persalinan yang indah, nyaman, aman, lancar, alami dan bebas trauma.

\section{UCAPAN TERIMA KASIH}

Terimakasih kami ucapkan kepada Direktur dan Kepala Pusat Penelitian dan Pengabmas Poltekkes Kemenkes Surakarta, atas dana dan support untuk terselenggaranya Pengabmas ini. Kami juga mengucapkan terimakasih banyak kepada Kepala Puskesmas Klaten Selatan yang telah memfasilitasi dengan baik kegiatan pelatihan ini sehingga dapat berjalan dengan lancar. Tak lupa kami mengucapkan terimakasih banyak kepada seluruh peserta tenaga Kesehatan baik dokter maupun bidan yang telah mengikuti kegiatan pelatihan ini dengan baik serta sangat antusias dan aktif selama kegiatan pelatihan berlangsung serta semua team pengabdian masayarakat yang sangat baik untuk kerjasamanya sehingga semua kegiatan dapat terlaksana dengan baik.

\section{DAFTAR RUJUKAN}

Andriyani, A. 2014. Pengaruh Kelas Hypnobirthing Terhadap Kecemasan Ibu Hamil Di Puskesmas Rawat Inap Kota Yogyakarta. UNPAD.

Christian, L.M. 2012. Psychoneuroimmunology in pregnancy: Immune pathways linking stress with maternal health, adverse birth outcomes, and fetal development. Neuroscience and Biobehavioral Reviews, 36 (1): 350-361

Cunningham, Mac Donald, G. 2005. William Obstetri. 22 ed. EGC: Jakarta.

Ferguson, S., Davis, D., Browne, J. 2013. Does antenatal education affect labour and 
birth? A structured review of the literature. Women and Birth, 26 (1): e5

Isbir, G.G., Serçekuş, P. 2017. The effects of intrapartum supportive care on fear of delivery and labor outcomes: A single-blind randomized controlled trial. Journal of Nursing Research, 25 (2): 112-119

Kuswandi, L. 2011. Keajaiban Hypnobirthing. Pustaka Bunda: Jakarta.

Muflihah, I.S. 2013. Hypnobirthing. Cakrawala Galuh, II (No 4): 66-60

Phillips-Moore, J. 2012. Birthing outcomes from an Australian hypno birthing programme. British Journal of Midwifery, 20 (8): 558-564

Potter, P. 2006. Fundamental Keperawatan, Konsep, Proses dan Praktik. 4 Vol 2 EGC: Jakarta.

Pengaruh Relaksasi Hypnobirthing Terhadap Kecemasan, Nyeri persalinan dan Apgar Score Bayi Baru lahir (2019). 2019. Ed. Puspita Sari, L., Rosalinna. Surakarta.

Swencionis, C., Rendell, S.L., Dolce, K., Massry, S., Mongan, M. 2012. Outcomes of HypnoBirthing. Journal of Prenatal \& Perinatal Psychology \& Health, 27 (2): 120

Uludağ, E., Mete, S. 2021. The effect of nursing care provided based on the philosophy of hypnobirthing on fear, pain, duration, satisfaction and cost of labor: a singleblind randomized controlled study: The effect of nursing care on the labor process and cost. Health Care for Women International, 42 (4-6): 678-690

WHO. (2015) "Global health Observatory". 